\title{
Assessment of hemostatic disturbances in women with established rheumatoid arthritis
}

\author{
Aleksandra Vranic ${ }^{1}$ - Iva Pruner ${ }^{2}$ - Mirjana Veselinovic ${ }^{3}$ - Nida Soutari ${ }^{4}$ - Anica Petkovic ${ }^{1}$ Vladimir Jakovljevic $^{5,6}$. \\ Aleksandra Antovic ${ }^{7,8}$
}

Received: 9 April 2019 /Revised: 15 May 2019 /Accepted: 29 May 2019/Published online: 17 June 2019

(C) The Author(s) 2019

\begin{abstract}
Objectives This study was aimed to assess hemostatic disturbances in female patients with established rheumatoid arthritis (RA) in relation to menopausal status and disease activity.

Method Ninety women were included in the study, 42 patients and 48 age-matched healthy controls. There were no differences between the investigated groups regarding the presence of traditional cardiovascular risk factors. Two global hemostatic assays were employed, namely endogenous thrombin potential (ETP) and overall hemostasis potential (OHP). The parameters of the ETP assay (ETP, C-max, t-lag, t-max) and OHP assay (overall coagulation potential (OCP) and overall fibrinolytic potential (OFP)) were assessed. Moreover, the parameters of the fibrin clot (lag time, Max Abs, and slope) were measured by clot turbidity and scanning electron microscopy (SEM). Both patients and controls were divided into four subgroups according to menopause status.

Results The premenopausal controls differed significantly from all other subgroups in terms of diminished levels of ETP $(p=$ $0.02)$, C-max $(p=0.01)$, OCP $(p=0.02)$, OHP $(p=0.001)$, and Max Abs $(p=0.008)$, while OFP $(p=0.0001)$ was increased. This tendency was not seen in the premenopausal RA patients compared with the postmenopausal RA patients. SEM images showed denser clots composed of thinner fibers in samples from RA patients. The disease activity measured by DAS28 correlated with OCP and OHP $(r=0.54 ; p=0.001$ and $r=0.44 ; p=0.003$, respectively) indicating persistent hypercoagulable condition in the whole group of RA patients.

Conclusions Our results point towards coagulation activation in premenopausal women with established RA. The patients were well characterized, which enabled assessment in a real-life setting.

Key Points

- Extensive assessment points towards persistent coagulation activation in premenopausal women with established rheumatoid arthritis.

- Impaired thrombin generation and fibrin formation are associated with menopause in healthy women, while rheumatoid arthritis closes the gap within patients regarding menopause.

- Fibrin morphology is unfavorably altered and fibrinolysis is decreased in patients with established rheumatoid arthritis.

- Increased activity of thrombin activatable fibrinolysis inhibitor (TAFI) may contribute to impaired fibrinolysis in patients with rheumatoid arthritis.
\end{abstract}

Keywords Fibrin structure $\cdot$ Hemostasis $\cdot$ Menopause $\cdot$ Rheumatoid arthritis

Aleksandra Antovic

aleksandra.antovic@ki.se

1 Faculty of Medical Sciences, Department of Pharmacy, University of Kragujevac, Kragujevac, Serbia

2 Department of Molecular Medicine and Surgery, Karolinska Institutet, Stockholm, Sweden

3 Faculty of Medical Sciences, Department of Internal Medicine, University of Kragujevac, Kragujevac, Serbia

4 Clinical Chemistry, Karolinska University Hospital, Stockholm, Sweden
5 Faculty of Medical Sciences, Department of Physiology, University of Kragujevac, Kragujevac, Serbia

6 1st Moscow State Medical, University IM Sechenov, Department of Human Pathology, Moscow, Russia

7 Department of Medicine, Rheumatology Unit, Karolinska Institutet, Stockholm, Sweden

8 Academic Specialist Center, Center for Rheumatology, Stockholm Health Services, Stockholm, Sweden 


\section{Introduction}

In addition to the progressive disability secondary to the joint impairment, the increased risk of cardiovascular disease (CVD) is a major issue in patients with rheumatoid arthritis (RA) [1]. RA is associated with most subtypes of CVD, and ischemic heart disease (IHD) and in particular myocardial infarction has been most extensively studied [2]. The risk of IHD is increased in both men and women with RA, and it seems to develop rather rapidly after disease onset [3]. Despite improvements in RA treatment and improved disease control, the risk for IHD has remained constant over time [4]. Cardiovascular events are also a major cause of mortality in patients with RA [5], and recent studies point towards an increased risk of venous thromboembolism and cerebrovascular disease in RA [6, 7]. The association with traditional risk factors for CVD does not entirely explain the prevalence of premature atherosclerosis and prothrombotic condition in this group of patients $[8,9]$. Disease-related risk factors that potentiate the inflammatory burden are also of importance, especially elevated levels of C-reactive protein (CRP) and erythrocyte sedimentation rate (ESR) [10,11], as well as the presence of extra-articular manifestations [12], and high disease activity is associated with low functional status $[13,14]$. The positivity for rheumatoid factor (RF) and antibodies to citrullinated protein antigens (ACPAs) has been associated with the risk of clinically significant CVD in RA [15-17].

Chronic systemic inflammation in RA shifts the hemostatic mechanisms in favor of thrombosis through activation of the coagulation system, inhibition of fibrinolysis, and decreased activity of anticoagulant pathways [18]. Inflammation and coagulation are closely related processes that significantly influence each other [19], and this interaction occurs at several levels, such as platelet activation, endothelial activation, the expression of adhesion molecules on endothelium, tissue factor expression on monocytes, excessive thrombin and fibrin formation, and formation of denser fibrin structures, as reviewed by Hoppe et al. [19]. Excessive accumulation of fibrin in the synovium, the vessel walls, and in other tissues represents a striking pathophysiological feature of RA.

Thus, the presence of prothrombotic condition due to persistent inflammatory stimulation in RA patients acts synergistically with traditional CVD risk factors and contributes to the increased CVD risk in RA. This is of particular importance knowing that RA occurs more commonly in women and frequently onsets in women of childbearing age, with a female to male ratio up to $4: 1$ in younger age groups, but nearing 1:1 after 60 years of age [20]. In addition, there is also significantly higher disease activity in the female population, with three times more rapid progression of RA-related disability than in men [21].

While the assessment of single hemostatic factors and/or inhibitors reveals only a small part of the complex hemostatic process, the new generation of global hemostatic assays offers a complete overview of hemostasis. The most widely used global hemostatic assay is measurement of the endogenous thrombin potential (ETP), which reflects the total amount and the kinetics of thrombin generated over time in the examined plasma sample. The results of this test reliably reflect thrombotic or bleeding potential [22]. On the other hand, the overall hemostatic potential (OHP) assay provides additional information concerning the rates of fibrin formation and fibrin degradation, demonstrating the balance between these two opposing hemostatic processes [23]. The turbidimetric curve reflects fibrin formation and can be used to assess fibrin clot properties, and the fibrin degradation curve can be a useful tool for measuring the clot lysis time (CLT).

We aimed this study, therefore, to assess hemostatic disturbances in female patients with established RA using global hemostatic assays and to identify fibrin clot properties in relation to the presence of traditional risk factors for CVD, disease activity, and menopause status.

\section{Material and methods}

\section{Study population}

Forty-two women with established RA referred to the outpatient clinic, Department of Rheumatology, Clinical Centre Kragujevac, Serbia, were included in the study (mean age $54.8 \pm 9.1$ years). RA was diagnosed according to the classification criteria of the American College of Rheumatology (ACR)/European League Against Rheumatism (EULAR) 2010 [24]. The exclusion criteria included a history of diabetes mellitus, malignancy, inflammatory disease (inflammatory bowel diseases, systemic lupus erythematosus, systemic sclerosis, vasculitis) except RA, liver or renal insufficiency, previous cerebrovascular or cardiovascular disorders (including inherited thrombophilia, antiphospholipid syndrome, and hyperhomocysteinemia), and venous thromboembolism. RA assessments included a detailed medical history, the presence of extra-articular disease, current disease activity assessed by the 28-point disease activity score (DAS28) [25], and physical function using the Health Assessment Questionnaire (HAQ) [26]. All current medications were recorded. Additionally, at the time of blood sampling, the patients were free of any medication known to influence hemostasis, and we ensured that no anticoagulants or antithrombotic agents (acetylsalicylic acid) were prescribed to these patients.

Forty-eight age and sex-matched healthy subjects (mean age $54.1 \pm 6.2$ years) were included in the study as controls. They were free from diabetes mellitus, malignancy, inflammatory disease including RA, and liver or renal insufficiency. All women included in the study were not taking oral contraceptives or hormone replacement treatment. 
All hormone factors were self-reported by the participants. Post-menopausal status was defined as cessation of menses for 12 months, as previously described [27].

The study was conducted in accordance with the principles outlined in the Declaration of Helsinki and principles of Good Clinical Practice (GCP). Written informed consent was obtained from all participants, and the study protocol was approved by the Ethics Committee of the Clinical Center Kragujevac, Serbia, prior to the onset of the study.

\section{Blood sampling}

Following at least a 10 -h fasting period, blood was collected in Vacutainer tubes containing 0.129 M sodium citrate (BD Vacutainer Blood Collection System) using 21-gauge needles (BD Vacutainer needles). Platelet-poor plasma was obtained within $60 \mathrm{~min}$ of sampling by centrifugation at $2000 \times \mathrm{g}$ for $15 \mathrm{~min}$ at room temperature and stored at $-70^{\circ} \mathrm{C}$. The frozen plasma samples were transported to the Karolinska Institutet, Clinical Chemistry-Coagulation, Department of Molecular Medicine and Surgery, Stockholm, Sweden, for further analysis.

\section{Global hemostatic assays}

\section{Determination of endogenous thrombin potential}

The ETP assay (Siemens Healthcare Diagnostics Products GmbH, Marburg, Germany) was performed on a BCS® XP System according to the manufacturer's instructions. From the thrombin generation curves, we obtained the following four parameters: ETP (as a measure of the total endogenously generated thrombin), $\mathrm{t}_{\text {lag }}$ (lag phase until initiation), $\mathrm{C}_{\max }$ (peak thrombin generation), and $\mathrm{t}_{\max }$ (time to peak thrombin generation) (Fig. 1a). The ETP values were calculated as the area under the thrombin generation curve and given as a percentage $(\%)$. The intra-assay and inter-assay coefficients of variation (CVs) for the normal plasma pool were $1.1 \%$ and $1.7 \%$, while for the hypocoagulable plasma pool these were $1.8 \%$ and $3.9 \%$, respectively.

\section{Determination of overall hemostatic potential}

We employed a modification of the assay described by $\mathrm{He}$ et al. [23] in order to assess OHP in plasma. Briefly, fibrin aggregation curves were constructed in the microplate using $140-\mu \mathrm{L}$ citrated plasma with the addition of $20 \mu \mathrm{L}$ of diluted phospholipid reagent (Phospholipid-TGT, Rossix, Sweden), 0.04-U/mL thrombin (Sigma-Aldrich, USA), and 17$\mathrm{mmol} / \mathrm{L} \mathrm{CaCl}_{2}$ with or without $300-\mathrm{ng} / \mathrm{mL}$ tissue plasminogen activator (t-PA) (Boehringer Ingelheim, Germany). Absorbance (Abs) at $405 \mathrm{~nm}$ was measured every $12 \mathrm{~s}$ for $60 \mathrm{~min}$. The area under the curve was calculated by summation of the Abs values (Abs-sum) and expressed as the OHP value (Fig. 1c). Two additional parameters were also analyzed - the overall coagulation potential (OCP), determined as the area under the fibrin aggregation curve obtained without the addition of t-PA (Fig. 1d), and the overall fibrinolysis potential (OFP), calculated as the difference between the two areas as OFP $(\%)=((\mathrm{OCP}-\mathrm{OHP}) / \mathrm{OCP}) \times 100$ (Fig. 1c $)$. The intra-assay and inter-assay $\mathrm{CVs}$ for OHP were $1.6 \%$ and $6.8 \%$ and for OCP were $1.2 \%$ and $5.7 \%$, respectively.

\section{Determination of clot lysis time}

CLT was determined based on the fibrin aggregation curve for the determination of OHP and was defined as the time from the midpoint of the clear-to-maximum turbid transition (which corresponds to the "clotting time") to the midpoint of the maximum turbid-to-clear transition. CLT was measured before and after the addition of a specific inhibitor of thrombin-activatable fibrinolysis inhibitor (TAFI), potato tuber carboxypeptidase inhibitor (PTCI; final concentration $50 \mathrm{mg} / \mathrm{mL}$ ) in order to indirectly determine the activity of TAFI (Fig. 1b).

\section{Analyses of fibrin clot formation}

Fibrin clot density and the rates of fibrin polymerization were assessed with the turbidimetric clotting assay according to the method described by Carter et al. [28]. The turbidimetric curve for determination of OCP was used to assess (1) lag time, defined as the time to the starting point of detectable fibrin formation, (2) the slope at the steepest part of the fibrin polymerization curve, reflecting the rate of lateral aggregation and the fiber formation phase, and (3) the maximum absorbance (Max Abs) as a measure of the clot density, defined as the increase in absorbance from baseline to the maximum value (Fig. 1b).

\section{Scanning electron microscopy}

The clots formed during fibrin generation for the determination of OCP were washed with PBS (phosphate-buffered saline) solution and fixed in $2.5 \%$ glutaraldehyde in Hepesbuffered saline for $60 \mathrm{~min}$ at room temperature and stored at $4{ }^{\circ} \mathrm{C}$. The samples were washed in distilled water and placed in $70 \%$ ethanol for $10 \mathrm{~min}, 95 \%$ ethanol for $10 \mathrm{~min}$, absolute ethanol for $15 \mathrm{~min}$, and in pure acetone for $10 \mathrm{~min}$ (all at room temperature) and then transferred to tetramethylsilane (Merck, Darmstadt, Germany) for $10 \mathrm{~min}$ and air dried. After drying, the samples were mounted on an aluminum stub and coated with carbon (Bal-Tec MED 010, Lichtenstein). Samples were analyzed under an Ultra 55 field emission scanning electron microscope (Carl Zeiss, Oberkochen, Germany) at $3 \mathrm{kV}$. 
Fig. 1 Schematic presentation of a endogenous thrombin potential (ETP). b clot lysis time with or without addition of potato tuber carboxypeptidase inhibitor (PTCI), c overall hemostasis potential (OHP) and overall fibrinolytic potential (OFP), and $\mathbf{d}$ overall coagulation potential (OCP). Abs, absorbance a

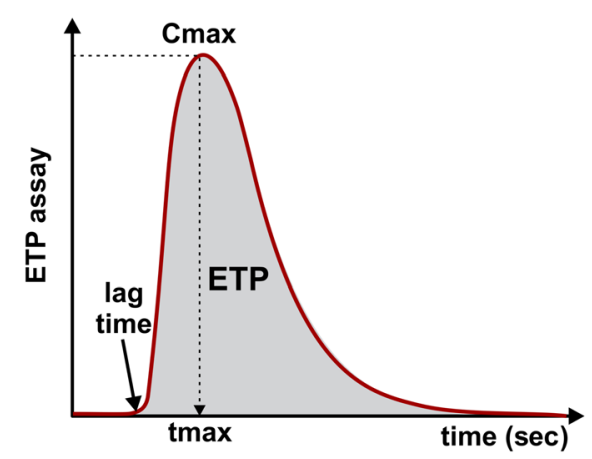

C

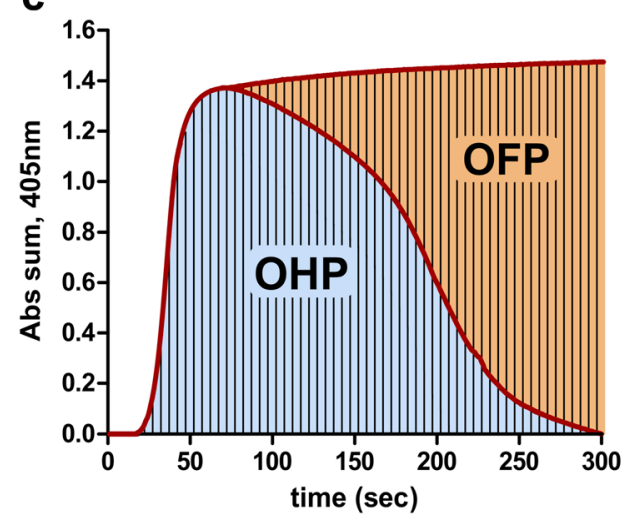

b

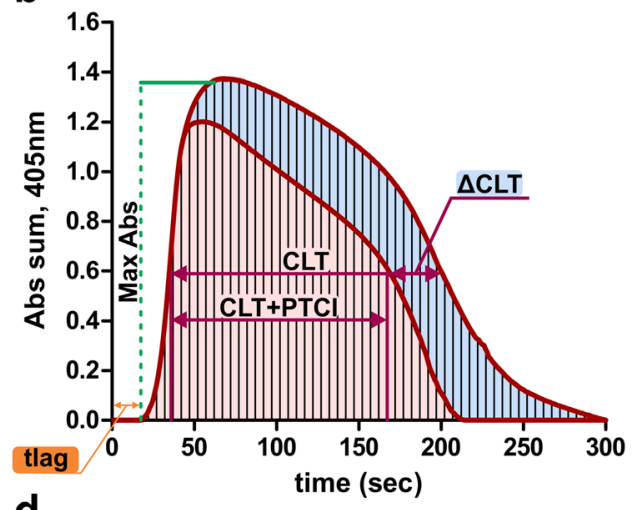

d

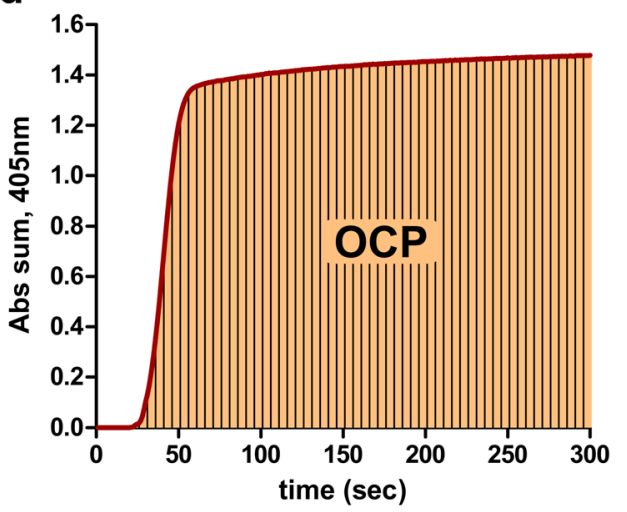

\section{Other laboratory analyses}

Laboratory analyses of CRP (Beckman Coulter AU680 analyzer), ESR (Westergren method, Vacuette ESR analyzer), fibrinogen concentration (Clauss method, ACL TOP analyzer by Instrumentation Laboratory), lipid profile (cholesterol, triglycerides, HDL, and LDL, all by Beckman Coulter AU680 analyzer), RF (turbidimetric method, Beckman Coulter A U 680 analyzer), and ACPA (Roche electrochemiluminescence immunoassay, Cobas e411 analyzer) were performed in the Central Laboratory of the Clinical Center Kragujevac.

\section{Statistical analysis}

All data were analyzed using SPSS 20.0 (IBM Corp. Released 2011) and GraphPad Prism 5 (Version for Windows, GraphPad Software, La Jolla, CA, USA). The results are expressed as means \pm standard deviation of the mean (SD), as medians with ranges and $95 \%$ confidence intervals, or as percentages depending on the data type and distribution. Distribution of the data was checked by the Shapiro-Wilk test. Independent samples $t$ tests (parametric) and Mann-Whitney $U$ tests (non-parametric) were used to assess the difference in estimated variables between groups. For comparison of more than two groups of individuals, one-way ANOVA was used. A $p$ value $<0.05$ was regarded as statistically significant.
Correlation between variables was examined using the Pearson and Spearman correlation analyses depending on the data type and distribution.

\section{Results}

\section{Characteristics of the study population}

The mean disease duration in patients was $12.8 \pm 8.0$ years, and disease activity was medium to high (DAS28 was $3.8 \pm$ 1.1) at the moment of blood sampling. The mean HAQ value was $1.3 \pm 0.2$, and the majority of patients were RF positive $(n=36 ; 86 \%)$ and ACPA positive $(n=40 ; 95 \%)$. All patients were treated with the standard treatment protocol of methotrexate (15-25 mg per week) and prednisolone ( $\leq 10 \mathrm{mg}$ per day); however, only 9 patients $(20 \%)$ were in remission (DAS28 <2.5). Five patients had extra-articular manifestations in form of rheumatoid nodules on the elbows and the small joints of the hands.

There were no differences between the controls and RA patients regarding the presence of traditional CVD risk factors of smoking ( $42 \%$ vs $41 \%$ ), hypertension ( $37.5 \%$ vs. $42.8 \%$ ), and body-mass index (BMI) $\left(26.1 \pm 3.9 \mathrm{~kg} / \mathrm{m}^{2}\right.$ vs. $26.1 \pm$ $\left.4.9 \mathrm{~kg} / \mathrm{m}^{2}\right)$ or regarding lipid profile, including cholesterol $(6.5 \pm 1.2 \mathrm{mmol} / \mathrm{L}$ vs. $6.1 \pm 1.0 \mathrm{mmol} / \mathrm{L})$, triglycerides $(1.5 \pm$ $0.6 \mathrm{mmol} / \mathrm{L}$ vs. $1.5 \pm 0.6 \mathrm{mmol} / \mathrm{L}), \mathrm{HDL}(1.6 \pm 0.3 \mathrm{mmol} / \mathrm{L}$ 
vs. $1.5 \pm 0.3 \mathrm{mmol} / \mathrm{L})$, and $\operatorname{LDL}(4.2 \pm 1.1 \mathrm{mmol} / \mathrm{L}$ vs. $3.8 \pm$ $0.9 \mathrm{mmol} / \mathrm{L})$.

As expected, patients with RA had higher CRP (11.5 \pm $6.4 \mathrm{mg} / \mathrm{L}$ vs. $2.5 \pm 2.4 \mathrm{mg} / \mathrm{L}, p=0.0001)$, ESR $(22.9 \pm$ $13.5 \mathrm{~mm} / \mathrm{h}$ vs. $13.3 \pm 8.8 \mathrm{~mm} / \mathrm{h}, p=0.0001)$, and fibrinogen levels $(3.5 \pm 0.7 \mathrm{~g} / \mathrm{L}$ vs. $3.2 \pm 0.5 \mathrm{~g} / \mathrm{L}, p=0.031)$ compared with controls.

Women in both groups were divided into the following four different subgroups according to menopause: (1) premenopausal controls $(n=14),(2)$ postmenopausal controls $(n=$ $34)$, (3) premenopausal patients $(n=11)$, and (4) postmenopausal patients $(n=31)$. The oldest menstruating control was 53 years old, and the youngest menopausal woman with RA was 45 years old. The postmenopausal controls had a mean cessation of menses of $8.2 \pm 4.1$ years, while in the postmenopausal patient group it was $9.3 \pm 4.5$ years, but this difference was not statistically significant.

Demographic and clinical characteristics of the participants as well as the presence of traditional CVD risk factors in these subgroups are presented in Table 1. Premenopausal women in subgroups 1 and 3 had lower BMI, LDL, and total cholesterol levels compared with postmenopausal women in subgroups 2 and 4. The levels of CRP, ESR, and fibrinogen were lower in premenopausal controls compared with postmenopausal women in the control group, but the difference ceased to exist in the RA group, as presented in Table 1.

\section{Hemostatic parameters}

The levels of the investigated parameters of the global hemostatic assays and the fibrin clot parameters did not differ between the controls and RA patients on the group level.

ETP levels were significantly higher in postmenopausal controls $(p=0.023)$ and were higher in both subgroups of RA patients compared with the levels in subgroup 1, but these differences were not statistically significant (Table 2). The levels of C-max, reflecting the maximum thrombin generation, had the same trend. Other parameters of the thrombin generation assay showed similar levels in the investigated subgroups. The parameters of thrombin generation were not correlated to the disease duration, or to the disease activity in the investigated patients with RA.

OHP (sum-Abs) was significantly lower ( $p=0.001 ; p=$ $0.04 ; p=0.03$, respectively), while OFP (\%) was significantly higher ( $p=0.0001 ; p=0.006 ; p=0.001$, respectively) in premenopausal controls (subgroup 1) compared with

Table 1 Demographic and clinical characteristics of the study population

\begin{tabular}{|c|c|c|c|c|}
\hline \multirow[t]{2}{*}{ Subjects characteristics } & \multicolumn{2}{|l|}{ Healthy controls } & \multicolumn{2}{|l|}{ Rheumatoid patients } \\
\hline & Premenopausal control (1) & Postmenopausal control (2) & Premenopausal patient (3) & Postmenopausal patient (4) \\
\hline Number of patients & 14 & 34 & 11 & 31 \\
\hline Average age & $47.0 \pm 2.9^{\mathrm{a} * *,}, \mathrm{c} * *$ & $57.1 \pm 4.7^{\mathrm{d} * *}$ & $43.6 \pm 6.2^{f_{* *}}$ & $58.8 \pm 6.1$ \\
\hline BMI $\left(\mathrm{kg} / \mathrm{m}^{2}\right)$ & $24.1 \pm 3.2^{\mathrm{a} *}, \mathrm{c}_{*}$ & $27 \pm 3.9^{\mathrm{d} *}$ & $23.6 \pm 4.7^{\mathrm{f}_{*}}$ & $27.1 \pm 4.7$ \\
\hline Disease duration (years) & / & 1 & $11.6 \pm 8.4$ & $13.2 \pm 7.9$ \\
\hline DAS28 & / & / & $3.6 \pm 1.4$ & $3.8 \pm 1.0$ \\
\hline HAQ & / & / & $1.21 \pm 0.21$ & $1.27 \pm 0.26$ \\
\hline RF positive, $n(\%)$ & / & / & $10(90.9)$ & $26(72.2)$ \\
\hline ACPA positive, $\mathrm{n}(\%)$ & / & / & $11(100)$ & $29(93.5)$ \\
\hline \multicolumn{5}{|l|}{ Smokers $n(\%)$} \\
\hline Current smokers & $7(50)$ & $14(41.2)$ & $5(45.5)$ & $12(38.7)$ \\
\hline Non-smokers & $6(42.9)$ & $13(38.2)$ & $6(54.5)$ & $13(41.9)$ \\
\hline Past smokers & $1(7.1)$ & $7(20.6)$ & 1 & $6(19.4)$ \\
\hline Cholesterol (mmol/L) & $5.8 \pm 1.0^{\mathrm{a} * *}$ & $6.8 \pm 1.2^{\mathrm{d} * *}$ & $5.5 \pm 0.9^{\mathrm{f}_{*}}$ & $6.3 \pm 1$ \\
\hline Triglycerides (mmol/L) & $1.4 \pm 0.4$ & $1.4(0.7-3.9)$ & $1.4(0.7-3.3)$ & $1.6 \pm 0.7$ \\
\hline $\mathrm{HDL}(\mathrm{mmol} / \mathrm{L})$ & $1.6 \pm 0.3$ & $1.6(1.2-2.5)^{\mathrm{d} *}$ & $1.3(1.1-2.0)$ & $1.5 \pm 0.3$ \\
\hline $\mathrm{LDL}(\mathrm{mmol} / \mathrm{L})$ & $3.5 \pm 0.9^{\mathrm{a} * *}$ & $4.5 \pm 1.1^{\mathrm{d} * *,}, \mathrm{e}_{*}$ & $3.5 \pm 0.8$ & $3.9 \pm 1$ \\
\hline $\operatorname{ESR}(\mathrm{mm} / \mathrm{h})$ & $11.2 \pm 10.3^{\mathrm{b} * *, \mathrm{c}_{* *}}$ & $14.2 \pm 8.1^{\mathrm{d} *,} \mathrm{e}_{* *}$ & $25.3 \pm 15.1$ & $22.1 \pm 13.1$ \\
\hline CRP (mg/L) & $1.8 \pm 1.1^{\mathrm{b} * *, \mathrm{c}_{* *}}$ & $2.8 \pm 2.7^{\mathrm{d} * *, \mathrm{e}_{*}}$ & $11.6 \pm 17.2$ & $6.7 \pm 9.2$ \\
\hline Fibrinogen $(\mathrm{g} / \mathrm{L})$ & $3.08 \pm 0.59^{\mathrm{b}} * *$ & $3.34 \pm 0.48^{\mathrm{d} *}$ & $3.77 \pm 0.57$ & $3.47 \pm 0.72$ \\
\hline
\end{tabular}

The values are expressed as means $\pm \mathrm{SD}$, or median (range), or number (percent) where is necessary. $B M I$, body mass index; DAS28, Disease Activity Score 28; $H A Q$, Health Assessment Questionnaire; $R F$, rheumatoid factor; $A C P A$, citrullinated protein antigen; $C R P$, C-reactive protein; $H D L$, highdensity lipoprotein; $L D L$, low-density lipoprotein; $E S R$, erythrocyte sedimentation rate; $C R P$, C-reactive protein. Single asterisk indicates statistical significance $(p<0.05)$; double asterisks indicate statistical significance $(p<0.01)$. Statistical significance between groups: ${ }^{\mathrm{a}} 1$ and $2 ;{ }^{\mathrm{b}} 1$ and $3 ;{ }^{\mathrm{c}} 1$ and 4 ; d 2 and $3 ;{ }^{\mathrm{e}} 2$ and $4 ;{ }^{\mathrm{f}} 3$ and 4 
Table 2 Parameters of global hemostatic methods in study population

\begin{tabular}{|c|c|c|c|c|}
\hline \multirow[b]{2}{*}{ Parameters } & \multicolumn{2}{|l|}{ Healthy controls } & \multicolumn{2}{|l|}{ Rheumatoid patients } \\
\hline & Premenopausal control (1) & Postmenopausal control (2) & Premenopausal patient (3) & Postmenopausal patient (4) \\
\hline OHP (Abs-sum) & $116.2 \pm 36.4^{\mathrm{a} * *, \mathrm{~b} *, \mathrm{c}_{*}}$ & $155.9 \pm 32.3$ & $151.5 \pm 44.7$ & $146.4 \pm 42$ \\
\hline OCP (Abs-sum) & $338 \pm 42.1^{\mathrm{a} *}$ & $372 \pm 40.8$ & $362.7 \pm 68.7$ & $358.1 \pm 59.8$ \\
\hline OFP $(\%)$ & $66.7 \pm 6.6^{\mathrm{a}_{* *}, \mathrm{~b}_{* *}, \mathrm{c}_{* *}}$ & $57.6 \pm 7.3$ & $58.6 \pm 6.1$ & $60.1(38.1-70.0)$ \\
\hline ETP AUC (\%) & $93.1 \pm 8^{\mathrm{a}_{*}}$ & $99.1 \pm 7.8$ & $97.9 \pm 7.9$ & $97 \pm 10.5$ \\
\hline ETP Cmax (\%) & $102.4 \pm 6.3^{\mathrm{a} *}$ & $109.8 \pm 9.3^{\mathrm{e} *}$ & $105.9 \pm 8.8$ & $104 \pm 11$ \\
\hline ETP tlag (sec) & $21.5 \pm 1.8$ & $22 \pm 2.3$ & $23.4 \pm 5.7$ & $21.5 \pm 3$ \\
\hline ETP tmax (sec) & $67.4 \pm 10.5$ & $65.7 \pm 12.3$ & $63.9 \pm 8.7$ & $67.5 \pm 14.9$ \\
\hline CLT (sec) & $20.2 \pm 3.7^{a_{*}, b_{*}, c_{*}}$ & $24.9(19.0-34.3)$ & $24.8 \pm 3.2$ & $23.5(19.8-36.7)$ \\
\hline CLT PTCI (sec) & $16.7 \pm 3^{\mathrm{a} *}$ & $18.8 \pm 2.9^{\mathrm{e}_{*}}$ & $18.1 \pm 3.8$ & $17.1 \pm 3$ \\
\hline$\Delta \mathrm{CLT}$ & $4.3 \pm 2^{\mathrm{a} *, \mathrm{~b}_{*}, \mathrm{c}_{* *}}$ & $5.9 \pm 2.9$ & $6.13 \pm 3.3$ & $6.9 \pm 3.7$ \\
\hline FC lag time (sec) & $262.3 \pm 60.2^{\mathrm{a}_{*}, \mathrm{~b}_{*}, \mathrm{c}_{*}}$ & $290.4 \pm 51.8$ & $330.5 \pm 96.2$ & $332.1 \pm 100.3$ \\
\hline FC Max Abs & $1.6 \pm 0.2^{\mathrm{a} * *}, \mathrm{~b}_{*}, \mathrm{c}_{*}$ & $1.7 \pm 0.2$ & $1.8 \pm 0.2$ & $1.7 \pm 0.2$ \\
\hline FC Slope & $76.4 \pm 24.8$ & $79.3 \pm 31.1^{\mathrm{d}_{*}, \mathrm{e}_{*}}$ & $61.8 \pm 27.9$ & $65.4 \pm 23$ \\
\hline
\end{tabular}

The values are expressed as means $\pm \mathrm{SD}$, or median (range). $O H P$, overall hemostasis potential; $O C P$, overall coagulation potential; $O F P$, overall fibrinolytic potential; ETP, endogenous thrombin potential, $A U C$, area under curve (referent value 87-128); Cmax, maximal thrombin concentration (referent values 82-119); tlag, time to beginning of thrombin formation; tmax, time to maximal thrombin concentration; CLT, clot lysis time; PTCI, potato tuber carboxypeptidase inhibitor; $\triangle C L T$, difference between CLT with PTCI and CLT without PTCI; lag time, time to starting point of detectable fibrin formation; $\max A b s$, increase in absorbance from baseline to maximum value; slope, the rate of lateral aggregation and fiber formation phase. Single asterisk indicates statistical significance $(p<0.05)$; double asterisks indicate statistical significance $(p<0.01)$. Statistical significance between groups: ${ }^{\text {a }} 1$ and $2 ;{ }^{\mathrm{b}} 1$ and $3 ;{ }^{\mathrm{c}} 1$ and $4 ;{ }^{\mathrm{d}} 2$ and $3 ;{ }^{\mathrm{e}} 2$ and $4 ;{ }^{\mathrm{f}} 3$ and 4

postmenopausal controls and to pre- and postmenopausal patients (subgroups 2-4). OCP (sum-Abs) was significantly lower in subgroup 1 compared with subgroup $2(p=0.018)$ (Table 2). When adjusted for BMI, the levels of all investigated parameters remained significantly different.

Typical fibrin aggregation curves for OCP and OHP in subjects from all investigated subgroups are presented on Fig. 2, demonstrating augmented fibrin aggregation (Figs. 2a) and diminished fibrinolysis (Fig. 2b) in patients compared with controls.

CLT was shorter in premenopausal controls compared with postmenopausal controls $(p=0.007)$ and RA patients $(p=0.002$ and $p=0.0001$, respectively, for both subgroups). After the addition of PTCI in the investigated samples, CLT remained significantly different between subgroups 1 and $2(p=0.03)$

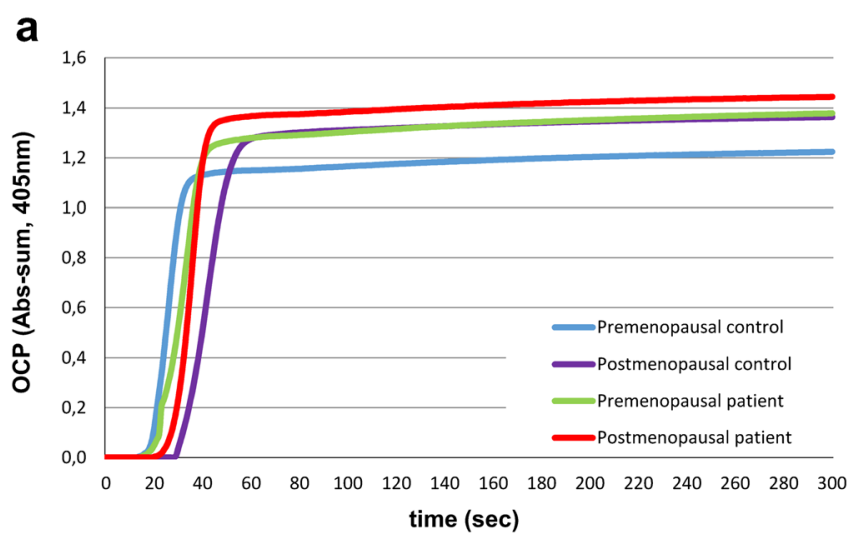

(Table 2). The difference in CLT before and after PTCI addition $(\triangle C L T)$ reflects the activity of TAFI in the investigated samples (Fig. 1b). Compared with premenopausal controls, $\triangle$ CLT was greater in postmenopausal controls $(p=0.03)$ and in both subgroups of RA patients ( $p=0.018$ and $p=0.009$, respectively), reflecting higher TAFI activity in these samples.

Levels of OCP and OHP correlated $(r=0.54 ; p=0.001$ and $r=0.44 ; p=0.003$, respectively) with the disease activity in RA patients as measured by the DAS28 (Fig. 3a). Significant correlation was also observed with the levels of inflammatory parameters CRP $(r=0.45 ; p=0.003$ for OCP and $r=0.46 ; p=0.002$ for OHP) and ESR ( $r=0.65 ; p=0.0001$ for OCP and $r=0.65$; $p=0.0001$ for OHP). OFP was inversely correlated with $\Delta$ CLT ( $r=-0.47, p=0.002$; Fig. $3 b)$ in RA patients, indicating that diminished fibrinolysis is related to increased TAFI activity.

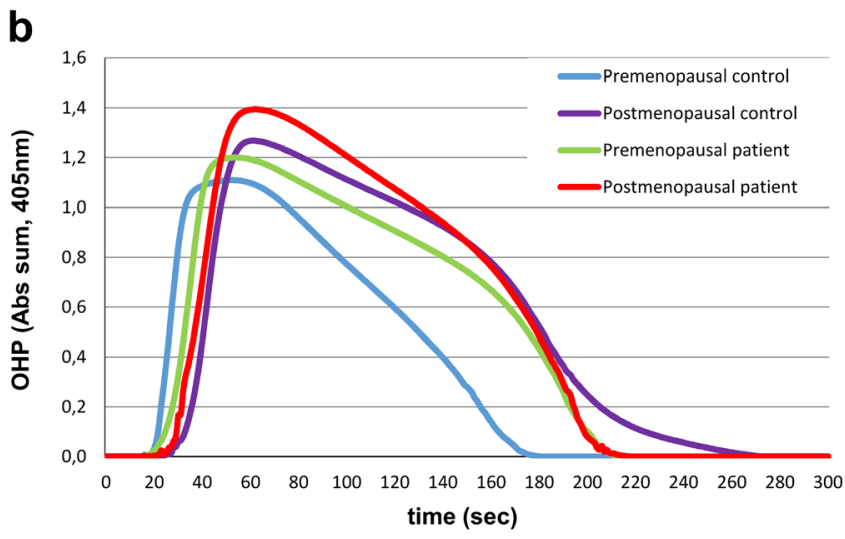

Fig. 2 Representative curves of fibrin formation for the assay of a overall coagulation potential (OCP) and $\mathbf{b}$ fibrin formation and fibrinolysis for the assay of overall hemostatic potential (OHP) in control subjects and patients with RA 
Fig.3 a Correlation between RA activity measured by DAS 28 and overall coagulation potential (OCP, blue) as well as overall hemostatic potential (OHP, red) in 42 patients with RA; $\mathbf{b}$ correlation between overall fibrinolysis potential (OFP) and differences in clot lysis time before and after addition of TAFI-inhibitor $(\triangle \mathrm{CLT})$

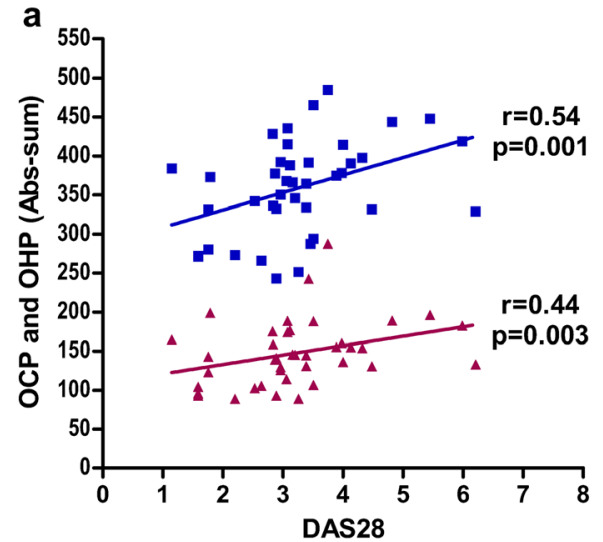

b

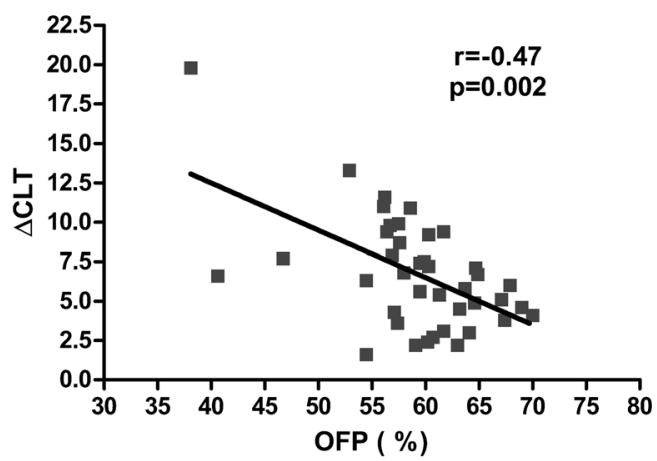

\section{Analysis of fibrin clot parameters and clot structure}

Parameters of fibrin clot formation indicated significantly shorter lag-time and lower Max Abs values in premenopausal controls compared with postmenopausal controls and to preand postmenopausal patients (Table 2). The slope of fibrin formation did not differ between control subgroups or between RA subgroups, but the slope values were higher in controls compared with patients (Table 2).

Scanning electron microscopy revealed that fibrin clots in premenopausal controls had larger pores with lower density, a so-called "looser" structure that is more susceptible to fibrinolysis (Fig. 4; 1a, b). Postmenopausal controls (Fig. 4; 2a, b) and both premenopausal (Fig. 4; 3a, b) and postmenopausal RA patients (Fig. 4; 4a, b) had denser fibrin structures with smaller pores. In these clots, fibers are tightly packed and are less prone to fibrinolysis.
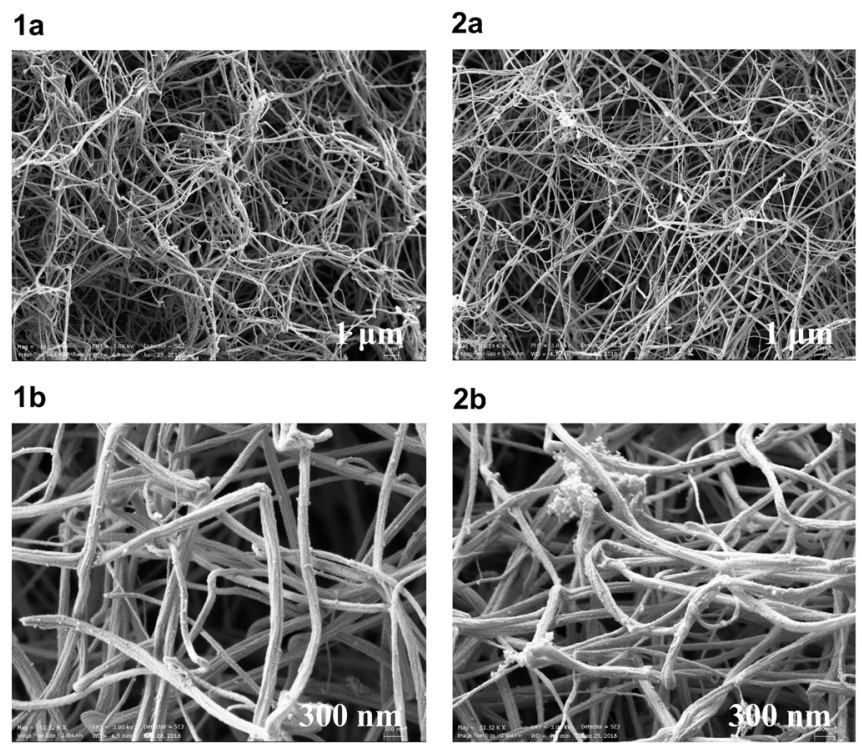

Fig. 4 Scanning electron microscopic images (SEM) of representative fibrin clots in investigated subjects. 1. Premenopausal control; 2. postmenopausal control; 3. premenopausal RA patient; 4.
Measurement of the fiber thickness of the representative samples was performed in five different areas, and the mean value of 10 fibers/area was used as the final measure of fiber thickness in these samples. Thicker fibers were found in the controls compared with patients (subgroup 1; $148.2 \mathrm{~nm} \pm$ $5.9 \mathrm{~nm}$ and subgroup 2; $132.6 \pm 18.2 \mathrm{~nm}$ vs. subgroup 3; $120.6 \pm 12.9 \mathrm{~nm}$ and subgroup $4 ; 127.1 \pm 8.1 \mathrm{~nm})$.

\section{Discussion}

We have explored hemostatic disturbances in women with established RA using two global hemostatic assays, and we have evaluated the fibrin clot structures in these patients. All results were compared with the results obtained from healthy age-matched women as well as within the groups regarding menopause status. Premenopausal healthy women had

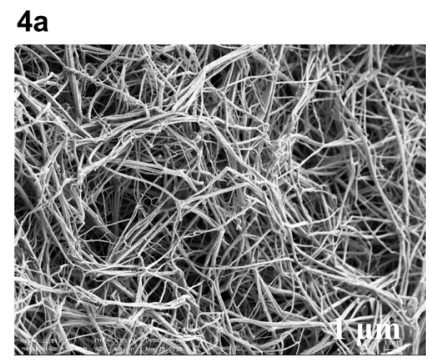

3b
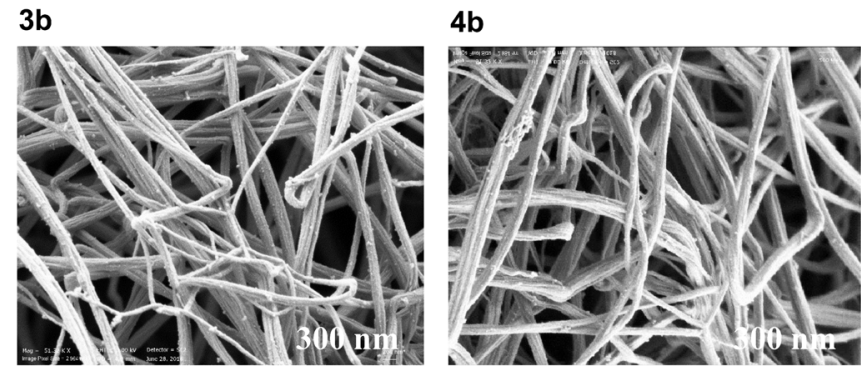

postmenopausal RA patient. The magnification $1 \mu \mathrm{m}$ was used for Figs. 1, 2, 3, and 4a and $300 \mathrm{~nm}$ for Figs. 1, 2, 3, and 4b 
reduced thrombin and fibrin formation, looser fibrin structure, and increased fibrinolysis compared with postmenopausal healthy controls. There were no significant differences between pre- and postmenopausal patients with RA. These findings might indicate that the inflammatory burden in women with RA activates hemostasis and closes the gap between preand postmenopausal RA patients regarding hemostatic activation.

The major advantage of our study is the extensive investigation of hemostatic parameters in a homogenous group of RA patients in comparison with strictly matched control subjects. This is of particular importance knowing that the CVD risk profile is altered in menopausal women [29]. Moreover, the levels of single coagulation factors increase, while the levels of natural anticoagulants decline with menopause in healthy women [30]. Regarding RA, the risk for disease onset is associated with an earlier age at menopause [31], and the postmenopausal period is related to higher disease activity and more rapid progression of disability [32, 33].

The lack of differences between the investigated parameters on the group level is probably due to ongoing treatment in patients with RA with standard protocols, including low doses of glucocorticoids and methotrexate. Treatment with methotrexate has been associated with a decreased risk of cardiovascular events [34], whereas assessments of the impact of glucocorticoid usage on CVD risk in patients with RA have yielded inconclusive results [35]. With regard to the effect on single coagulation parameters, no comprehensive data have been reported on the effect of RA therapies such as DMARDs and biologic agents, including TNF inhibitors. Studies in patients with RA treated with infliximab found reduced expression of proinflammatory cytokines together with reduced levels of fibrinogen and D-dimer and normalized levels of tissue-type plasminogen activator t-PA and plasminogen activator inhibitor- 1 in these patients during follow-up of treatment [36, 37]. These findings support the notion that expression of hemostatic markers changes during immune activation and is likely to normalize in response to therapy.

Only a few studies have investigated hemostatic balance by means of global hemostatic assays. Undas et al. explored thrombin generation capacity and indicated delayed but augmented thrombin bursts in samples from RA patients, mainly owing to enhanced coagulation factor VIII in these patients [38]. In contrast, the results of Kern et al. showed earlier and accelerated formation of a reduced amount of thrombin in a homogenous group of RA patients compared with healthy controls [39]. In addition, our data demonstrate lower levels of generated thrombin and peak of thrombin generation in premenopausal controls compared with postmenopausal controls and RA patients. Within the RA group, no correlations were observed between the investigated parameters of thrombin generation and disease activity, disease duration, or inflammatory markers such as CRP and ESR. Once again, this might be a consequence of the ongoing immunosuppressive treatment modulating the hemostatic response in the investigated group of patients. Taken together, the observed changes in thrombin generation in these studies are important and might be considered as an important aspect of the procoagulant state in RA.

The levels of the investigated parameters of overall hemostatic potential assay (OCP and OHP) correlated with disease activity in RA patients. The assay is based on fibrin aggregation and lysis, reflecting the total amount of fibrin formed in the investigated samples, and on its susceptibility to lysis. Fibrin formation is the final product of the coagulation process, but also an important step in early immunopathogenesis in the RA synovium, and fibrin is the most abundant antigen in the synovial compartment that can undergo citrullination and act as an autoantigen. In addition, the generation of a stable fibrin network is necessary to control the inflammatory process because fibrin clots act as a migratory matrix for various cell types such as macrophages [40].

The formation of tighter fibrin clots is connected with increased risk for CVD because these clots are less prone to fibrinolysis [41]. Menopause also seems to be related to the formation of prothrombotic fibrin clots [42], and KwasnyKrochin et al. demonstrated lower clot permeability and denser fibrin structure in RA patients compared with control samples [43]. Accordingly, we found an unfavorably altered fibrin morphology in RA patients with a compact structure composed of thinner fibers and with smaller intrinsic pores, especially when compared with the premenopausal control sample. These clots are difficult to lyse, which is reflected by diminished OFP and prolonged CLT in the investigated samples from RA patients. Further explanation for reduced fibrinolysis can be found in the augmented TAFI activity demonstrated in our study. TAFI is carboxypeptidase B, an enzyme involved in the cross-talk between coagulation and fibrinolysis, but it also plays a critical role in inflammatory processes as a complement inhibitor [44]. In a mouse model of autoimmune arthritis, TAFI exerted antiinflammatory effects by cleaving $\mathrm{C} 5 \mathrm{a}$, which is the final product of the complement cascade [44]. Thus, TAFI activation due to increased thrombin generation in RA inhibits fibrinolysis, but it might also reduce the inflammatory burden in RA. Further studies are needed to confirm this dual role of TAFI.

In summary, this extensive assessment points towards persistent coagulation activation in premenopausal women with established RA. The major limitation of our study is small number of investigated subjects. However, the patients were well characterized for the presence of traditional CVD risk factors and ongoing medications and had moderate to high disease activity, thus enabling an assessment in a real-life setting. Premenopausal patients with established RA had impaired fibrin structure compared with control subjects, and it resembled the clot structure in postmenopausal patients. Larger studies are needed to confirm these preliminary findings. 


\section{Compliance with ethical standards}

Disclosures None.

Informed consent The study was conducted in accordance with the principles outlined in the Declaration of Helsinki and principles of Good Clinical Practice (GCP). Written informed consent was obtained from all participants, and the study protocol was approved by the Ethics Committee of the Clinical Center Kragujevac, Serbia, prior to the onset of the study.

Open Access This article is distributed under the terms of the Creative Commons Attribution 4.0 International License (http:// creativecommons.org/licenses/by/4.0/), which permits unrestricted use, distribution, and reproduction in any medium, provided you give appropriate credit to the original author(s) and the source, provide a link to the Creative Commons license, and indicate if changes were made.

\section{References}

1. Lauper K, Gabay C (2017) Cardiovascular risk in patients with rheumatoid arthritis. Semin Immunopathol 39:447-449. https:// doi.org/10.1007/s00281-017-0632-2

2. Solomon DH, Goodson NJ, Katz JN, Weinblatt ME, Avorn J, Setoguchi S, Canning C, Schneeweiss S (2006) Patterns of cardiovascular risk in rheumatoid arthritis. Ann Rheum Dis 65:16081612. https://doi.org/10.1136/ard.2005.050377

3. Holmqvist ME, Wedren S, Jacobsson LT et al (2010) Rapid increase in myocardial infarction risk following diagnosis of rheumatoid arthritis amongst patients diagnosed between 1995 and 2006. J Intern Med 268:578-585. https://doi.org/10.1111/j.1365-2796. 2010.02260.x

4. Holmqvist M, Ljung L, Askling J (2017) Acute coronary syndrome in new-onset rheumatoid arthritis: a population-based nationwide cohort study of time trends in risks and excess risks. Ann Rheum Dis 76:1642-1647. https://doi.org/10.1136/annrheumdis-2016211066

5. Goodson N, Marks J, Lunt M, Symmons D (2005) Cardiovascular admissions and mortality in an inception cohort of patients with rheumatoid arthritis with onset in the 1980s and 1990s. Ann Rheum Dis 64:1595-1601. https://doi.org/10.1136/ard.2004. 034777

6. Wolfe F, Freundlich B, Straus WL (2003) Increase in cardiovascular and cerebrovascular disease prevalence in rheumatoid arthritis. $\mathrm{J}$ Rheumatol 30:36-40

7. Zöller B, Li X, Sundquist J, Sundquist K (2012) Autoimmune diseases and venous thromboembolism: a review of the literature. Am J Cardiovasc Dis 2:171-183

8. Boyer JF, Gourraud PA, Cantagrel A, Davignon JL, Constantin A (2011) Traditional cardiovascular risk factors in rheumatoid arthritis: a meta-analysis. Joint Bone Spine 78:179-183. https://doi.org/ 10.1016/j.jbspin.2010.07.016

9. Baghdadi LR, Woodman RJ, Shanahan EM, Mangoni AA (2015) The impact of traditional cardiovascular risk factors on cardiovascular outcomes in patients with rheumatoid arthritis: a systematic review and meta-analysis. PLoS One 10:e0117952. https://doi.org/ 10.1371/journal.pone.0117952

10. Wallberg-Jonsson S, Johansson H, Ohman ML, RantapaaDahlqvist S (1999) Extent of inflammation predicts cardiovascular disease and overall mortality in seropositive rheumatoid arthritis. A retrospective cohort study from disease onset. J Rheumatol 26: 2562-2571
11. Gonzalez-Gay MA, Gonzalez-Juanatey C, Lopez-Diaz MJ, Piñeiro A, Garcia-Porrua C, Miranda-Filloy JA, Ollier WER, Martin J, Llorca J (2007) HLA-DRB1 and persistent chronic inflammation contribute to cardiovascular events and cardiovascular mortality in patients with rheumatoid arthritis. Arthritis Care Res 57:125-132. https://doi.org/10.1002/art.22482

12. Turesson C, Mcclelland RL, Christianson TJ, Matteson EL (2007) Severe extra-articular disease manifestations are associated with an increased risk of first ever cardiovascular events in patients with rheumatoid arthritis. Ann Rheum Dis 66:70-75. https://doi.org/10. 1136/ard.2006.052506

13. Radovits BJ, Popa-Diaconu DA, Popa C, Eijsbouts A, Laan RFJM, van Riel PLCM, Fransen J (2009) Disease activity as a risk factor for myocardial infarction in rheumatoid arthritis. Ann Rheum Dis 68:1271-1276. https://doi.org/10.1136/ard.2008.089862

14. Farragher TM, Lunt M, Bunn DK, Silman AJ, Symmons DP (2007) Early functional disability predicts both all-cause and cardiovascular mortality in people with inflammatory polyarthritis: results from the Norfolk Arthritis Register. Ann Rheum Dis 66:486-492. https:// doi.org/10.1136/ard.2006.056390

15. Ajeganova S, Andersson ML, Frostegard J, Hafstrom I (2013) Disease factors in early rheumatoid arthritis are associated with differential risks for cardiovascular events and mortality depending on age at onset: a 10-year observational cohort study. J Rheumatol 40:1958-1966. https://doi.org/10.3899/jrheum.130365

16. Liang KP, Maradit Kremers H, Crowson CS et al (2009) Autoantibodies and the risk of cardiovascular events. J Rheumatol 36:2462-2469. https://doi.org/10.3899/jrheum.090188

17. Lopez-Longo FJ, Oliver-Minarro D, De La Torre I et al (2009) Association between anti-cyclic citrullinated peptide anti-bodies and ischemic heart disease in patients with rheumatoid arthritis. Arthritis Rheum 61:419-424. https://doi.org/10.1002/art.24390

18. Van den Oever IA, Sattar N, Nurmohamed MT (2014) Thromboembolic and cardiovascular risk in rheumatoid arthritis: role of the hemostatic system. Ann Rheum Dis 73:954-957. https://doi.org/10.1136/annrheumdis-2013-204767

19. Hoppe B, Dörner T (2012) Coagulation and the fibrin network in rheumatic disease: a role beyond hemostasis. Nat Rev Rheumatol 8: 738-746. https://doi.org/10.1038/nrrheum.2012.184

20. Solomon DH, Karlson EW, Rimm EB, Cannuscio CC, Mandl LA, Manson JAE, Stampfer MJ, Curhan GC (2003) Cardiovascular morbidity and mortality in women diagnosed with rheumatoid arthritis. Circulation 107:1303-1307. https://doi.org/10.1161/01.CIR. 0000054612.26458.B2

21. Sokka T, Toloza S, Cutolo M, Kautiainen H, Makinen H, Gogus F, Skakic V, Badsha H, Peets T, Baranauskaite A, Géher P, Ujfalussy I, Skopouli FN, Mavrommati M, Alten R, Pohl C, Sibilia J, Stancati A, Salaffi F, Romanowski W, Zarowny-Wierzbinska D, Henrohn D, Bresnihan B, Minnock P, Knudsen LS, Jacobs JW, Calvo-Alen J, Lazovskis J, Pinheiro Gda R, Karateev D, Andersone D, Rexhepi S, Yazici Y, Pincus T, QUEST-RA Group (2009) Women, men, and rheumatoid arthritis: analyses of disease activity, disease characteristics, and treatments in the QUEST-RA study. Arthritis Res Ther 11(1):R7. https://doi.org/10.1186/ar2591

22. Hemker HC, Al Dieri R, De Smedt E, Beguin S (2006) Thrombin generation, a function test of the hemostatic-thrombotic system. Thromb Haemost 96:553-561

23. He S, Antovic A, Blombäck M (2001) A simple and rapid laboratory method for determination of hemostasis potential in plasma - II Modifications for use in routine laboratories and research work. Thromb Res 103:355-361. https://doi.org/10.1016/S00493848(01)00332-2

24. Aletaha D, Neogi T, Silman AJ, Funovits J, Felson DT, Bingham CO, Birnbaum NS, Burmester GR, Bykerk VP, Cohen MD, Combe B, Costenbader KH, Dougados M, Emery P, Ferraccioli G, Hazes JM, Hobbs K, Huizinga TW, Kavanaugh A, Kay J, Kvien TK, 
Laing T, Mease P, Menard HA, Moreland LW, Naden RL, Pincus T, Smolen JS, Stanislawska-Biernat E, Symmons D, Tak PP, Upchurch KS, Vencovsky J, Wolfe F, Hawker G (2010) 2010 rheumatoid arthritis classification criteria: an American College of Rheumatology/European League Against Rheumatism collaborative initiative. Ann Rheum Dis 69:1580-1588. https://doi.org/10. 1136/ard.2010.138461

25. Prevoo ML, van't Hof MA, Kuper HH, van Leeuwen MA, van de Putte LB, van Riel PL (1995) Modified disease activity scores that include twenty-eight-joint counts. Development and validation in a prospective longitudinal study of patients with rheumatoid arthritis. Arthritis Rheum 38:44-48. https://doi.org/10.1002/art.1780380107

26. Kirwan JR, Reeback JS (1986) Stanford health assessment questionnaire modified to assess disability in British patients with rheumatoid arthritis. Br J Rheumatol 25:206-209. https://doi.org/10. 1093/rheumatology/25.2.206

27. Phipps AI, Ichikawa L, Bowles EJ et al (2010) Defining menopausal status in epidemiologic studies: a comparison of multiple approaches and their effects on breast cancer rates. Maturitas 67:6066. https://doi.org/10.1016/j.maturitas.2010.04.015

28. Carter AM, Cymbalista CM, Spector TD, Grant PJ, EuroCLOT Investigators (2007) Heritability of formation, morphology, and lysis: the EuroCLOT study. Arterioscler Thromb Vasc Biol 27: 2783-2789. https://doi.org/10.1161/ATVBAHA.107.153221

29. Newson L (2018) Menopause and cardiovascular disease. Post Reprod Health 24(1):44-49. https://doi.org/10.1177/ 2053369117749675

30. Renda G, Patti G, Lang IM, Siller-Matula JM, Hylek EM, Ambrosio G, Haas S, de Caterina R, Working Group on Thrombosis of the Italian Society of Cardiology (2019) Thrombotic and hemorrhagic burden in women: gender-related issues in the response to antithrombotic therapies. Int J Cardiol S0167-5273(18):35120-35129. https://doi.org/10.1016/j.ijcard. 2019.02.004

31. Pikwer M, Bergström U, Nilsson JA, Jacobsson L, Turesson C (2012) Early menopause is an independent predictor of rheumatoid arthritis. Ann Rheum Dis 71:378-381. https://doi.org/10.1136/ard. 2011.200059

32. Kuiper S, van Gestel AM, Swinkels HL, de Boo TM, da Silva JA, van Riel PL (2001) Influence of sex, age, and menopausal state on the course of early rheumatoid arthritis. J Rheumatol 28:1809-1816

33. Mollard E, Pedro S, Chakravarty E, Clowse M, Schumacher R, Michaud K (2018) The impact of menopause on functional status in women with rheumatoid arthritis. Rheumatology (Oxford) 57: 798-802. https://doi.org/10.1093/rheumatology/kex526

34. Westlake S, Colebatch A, Baird J et al (2010) The effect of methotrexate on cardiovascular disease in patients with rheumatoid arthritis: a systematic literature review. Rheumatology (Oxford) 49: 295-307. https://doi.org/10.1093/rheumatology/kep366

35. Ruyssen-Witrand A, Fautrel B, Saraux A, Le Loet X, Pham T (2011) Cardiovascular risk induced by low-dose corticosteroids in rheumatoid arthritis: a systematic literature review. Joint Bone Spine 78:23-30. https://doi.org/10.1016/j.jbspin.2010.02.040

36. Ingegnoli F, Fantini F, Griffini S, Soldi A, Pl M, Cugno M (2010) Anti-tumor necrosis factor alpha therapy normalizes fibrinolysis impairment in patients with active rheumatoid arthritis. Clin Exp Rheumatol 28:254-257

37. Agirbasli M, Inanc N, Baykan OA, Direskeneli H (2006) The effects of TNF alpha inhibition on plasma fibrinolytic balance in patients with chronic inflammatory rheumatic disorders. Clin Exp Rheumatol 24:580-583

38. Undas A, Gissel M, Kwasny-Krochin B, Gluszko P, Mann KG, Brummel-Ziedins KE (2010) Thrombin generation in rheumatoid arthritis: dependence on plasma factor composition. Thromb Haemost 104:224-230. https://doi.org/10.1160/TH10-02-0091

39. Kern A, Balog A, Dulic S, Barabás E, Kiszelák M, Vásárhelyi B (2016) Alterations of the thrombin generation profile in rheumatoid arthritis. J Thromb Thrombolysis 41:359-364. https://doi.org/10. 1007/s11239-015-1251-1

40. Lanir N, Ciano PS, Van de Water L, McDonagh J, Dvorak AM, Dvorak HF (1988) Macrophage migration in fibrin gel matrices. II. Effects of clotting factor XIII, fibronectin, and glycosaminoglycan content on cell migration. J Immunol 140:2340-2349

41. Collet JP, Allali Y, Lesty C, Tanguy ML, Silvain J, Ankri A, Blanchet B, Dumaine R, Gianetti J, Payot L, Weisel JW, Montalescot G (2006) Altered fibrin architecture is associated with hypofibrinolysis and premature coronary atherothrombosis. Arterioscler Thromb Vasc Biol 26:2567-2573. https://doi.org/10. 1161/01.ATV.0000241589.52950.4c

42. Piróg MM, Milewicz T, Jach R, Undas A (2016) Plasma fibrin clot properties in postmenopausal women: effects of hormone therapy. Menopause 23:511-517. https://doi.org/10.1097/GME. 0000000000000585

43. Kwasny-Krochin B, Gluszko P, Undas A (2010) Unfavorably altered fibrin clot properties in patients with active rheumatoid arthritis. Thromb Res 126(1):e11-e16. https://doi.org/10.1016/j. thromres.2010.04.007

44. Song JJ, Hwang I, Cho KH, Garcia MA, Kim AJ, Wang TH, Lindstrom TM, Lee AT, Nishimura T, Zhao L, Morser J, Nesheim M, Goodman SB, Lee DM, Bridges SL Jr, Gregersen PK, Leung LL, Robinson WH (2011) Plasma carboxypeptidase B downregulates inflammatory responses in autoimmune arthritis. J Clin Invest 121(9):3517-3527. https://doi.org/10.1172/JCI46387

Publisher's note Springer Nature remains neutral with regard to jurisdictional claims in published maps and institutional affiliations. 